\title{
Ray Amputation for Macrodractyly of the Foot: An Effective Treatment in an Environment With Limited Resources
}

\section{Kapay Kibadi*}

Head of Unit of Plastic Reconstructive and Aesthetic Surgery, Hand Surgery and Burns, University Clinics of Kinshasa, University of Kinshasa, Democratic Republic of Congo

\begin{abstract}
Macrodactyly represents a rare congenital anomaly characterized by distal limb overgrowth of all tissue elements. This should be distinguished from secondary digital/limb enlargement that occurs in vascular anomalies or as a result of other syndromes. Macrodactyly is defined by an elargement of all the structures of fingers or toes and characterized by hypertrophy of the bones and surrounding soft tissues in one or more digits. The aim of treatment is to obtain a cosmetic and functional foot. We present four cases of severe toe macrodactyly on which we performed ray amputation. Postoperative cosmetic and functional results were good in four cases. Ray amputation for macrodractyly of the foot is an effective treatment in an environment with limited resources.
\end{abstract}

Keywords: Macrodactyly; Distal limb

\section{Introduction}

Macrodactyly represents a rare congenital anomaly characterized by distal limb overgrowth of all tissue elements. This should be distinguished from secondary digital/limb enlargement that occurs in vascular anomalies or as a result of other syndromes. Macrodactyly is defined by an elargement of all the structures of fingers or toes and characterized by hypertrophy of the bones and surrounding soft tissues in one or more digits $[1,2]$.

Digital enlargement can also occur as part of different conditions including neurofibromatosis, hemangiomatosis, arteriovenous malformations, congenital lymphedema, Klippel-Trenaunay-Weber and Proteus syndromes [3]. Two types of macrodactyly, namely, static and progressive types, have been described [4]. In the static type, the growth rate of the involved digit is the same as the normal digits whereas in the progressive type, growth is accelerated compared to the rest. The progressive type is less common and involvement of the metacarpal and metatarsal bones is more likely in the progressive type [5]. Abnormal accelerated growth usually ceases at puberty $[5,6]$.

The aim of treatment is to obtain a pain-free and functional foot. Suggested procedures include digit amputation, epiphysiodesis, and debulking of soft tissues accompanied by total or segmental resection of distal phalanx and ray amputation [7-10]. The gool of this paper is to present the cosmetic and functional results of four patients who underwent ray amputation due to macrodactyly in the foot, in a medical and surgical environment with limited resources.

\section{Case Reports}

We present four patients with macrodactyly of the foot who were admitted and treated to our Unit of Plastic Reconstructive and Aesthetic Surgery, Hand Surgery and Burns, University Clinics of Kinshasa in Democratic Republic of Congo between 2010 and 2014.

\section{First patient}

The patient was a 17 yo male who presented with macrodactyly involving the 1st and 2nd toe. Because of massive enlargement of these digits, shoes of different sizes had to be worn and he complained of difficulty walking. X-rays demonstrated marked enlargement of all phalanges of the involved digits and mild metatarsal enlargement as well. He was treated with a ray amputation of second toe with adjacent

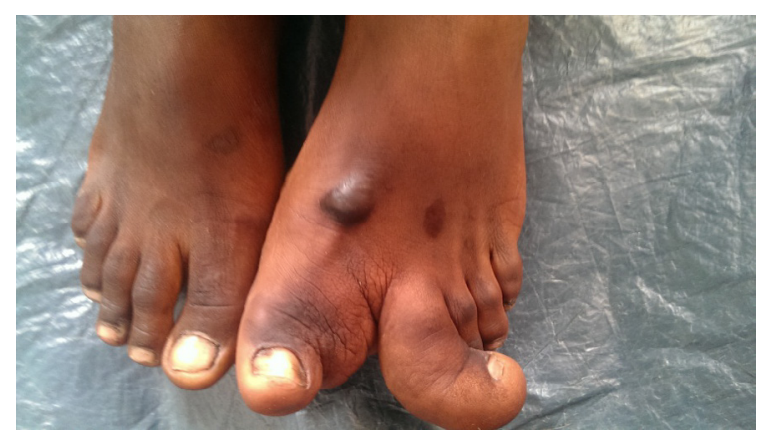

Figures 1: Patient, 17 years old, male. Hypertrophy overall 1st and 2nd toes. Treatment: Ray amputation of $2^{\text {nd }}$ toe.

soft-tissue debulking to allow for narrowing of the foot. Findings at surgery included enlargement of the bones, and tendons as well as marked excess subcutaneous fibrofatty tissue. No vascular lesions were noted. He healed without complication and at 1 year follow-up demonstrated normal ambulation and activities of daily living. He was satisfied with the appearance of his foot and was able to wear normal footwear of equivalent size (Figure 1).

\section{Second patient}

The second patient was 11 years old, female with hypertrophy overall 1st and 2nd toes on both the bone soft tissue, distorting both toes with hyper extension (Figure 2). It was congenital anomaly. Plain radiography remains the gold standard amount an increase in size in width and length of the phalanges reached. Ray Amputation of the foot was the treatment. The patient has evolved with healing of surgical

${ }^{*}$ Corresponding author: Kapay Kibadi, MD, PhD, Plastic Surgeon, Head of Unit of Plastic Reconstructive and Aesthetic Surgery, Hand Surgery and Burns, University Clinics of Kinshasa, University of Kinshasa, Democratic Republic of Congo, Tel: 00243817212310; E-mail: akibadi@yahoo.fr

Received October 01, 2014; Accepted November 10, 2014; Published November 17,2014

Citation: Kibadi K (2014) Ray Amputation for Macrodractyly of the Foot: An Effective Treatment in an Environment With Limited Resources. Surgery Curr Res 4: 211. doi:10.4172/2161-1076.1000211

Copyright: $\odot 2014$ Kibadi K, et al. This is an open-access article distributed under the terms of the Creative Commons Attribution License, which permits unrestricted use, distribution, and reproduction in any medium, provided the original author and source are credited. 


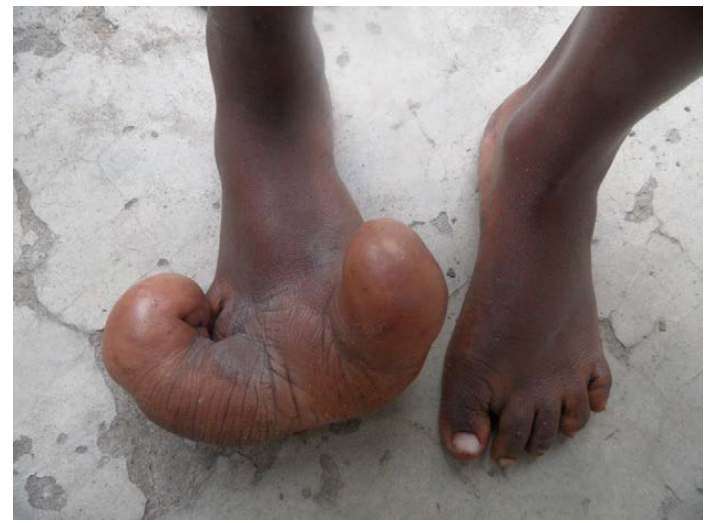

Figure 2: Patient, 11 years old, female. Hypertrophy overall 1st and 2nd toes on both the bone soft tissue, distorting both toes with hyper extension. Treatment- Ray amputation.

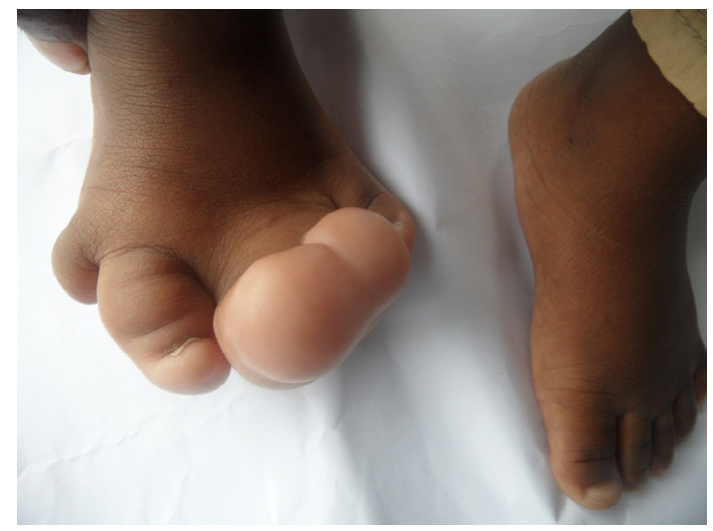

Figure 3: Patient, 3 yeras old, female. Overall enlarged $2^{\text {nd }}, 3^{\text {rd }}$ and $4^{\text {th }}$ toes associated with syndactyly of $2^{\text {nd }}$ and $3^{\text {rd }}$ toes on both the bone soft tissue, distorting both toes with hyper extension.

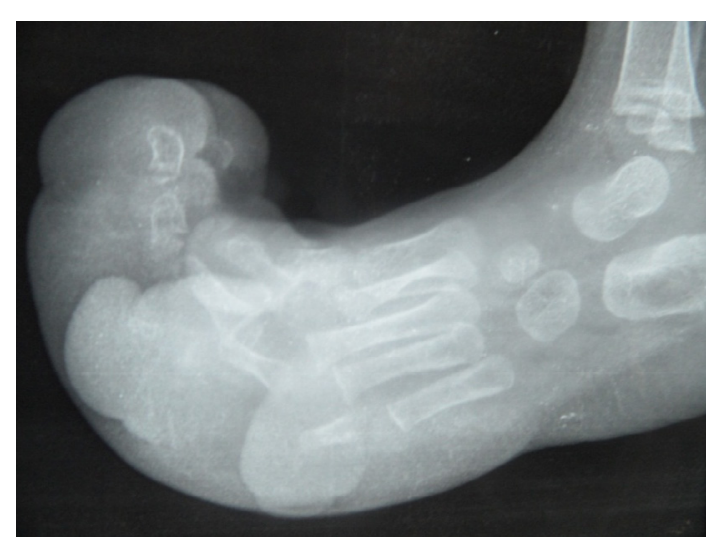

Figure 4: The same patient (3 yeras old, female). Plain radiography remains the gold standard amount an increase in size in width and length of the phalanges reached.

wounds and recovery of walking with wearing slippers. The follow-up was of 10 months.

\section{Third patient}

The third patient was 3 yeras old, female with overall enlarged 2nd, 3rd and 4th toes associated with syndactyly of 2nd and 3rd toes on both the bone soft tissue, distorting both toes with hyper extension (Figure 3 ). It was congenital anomaly. The radiography showed the increase in size in width and length of the phalanges reached (Figure 4). The treatment was the ray amputation of 2 nd and 3rd toes (Figure 5) with good cosmetic results after treatment (Figure 6). The follow-up was of 12 months.

\section{Fourth patient}

The fourth patient was 6 yeras old, female with macrodactyly of 2nd toe alone (Figure 7). It was congenital anomaly. The radiography

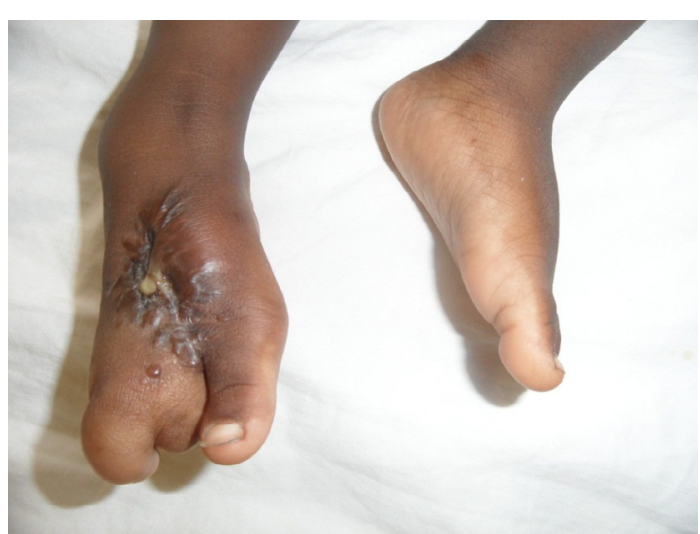

Figure 5: The same patient ( 3 yeras old, female). Functional results afte treatment (ray amputation of 2 nd and 3rd toes).

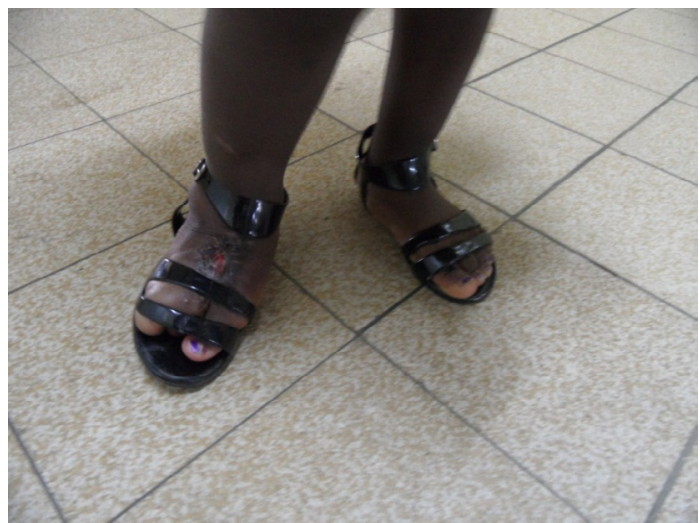

Figure 6: The same patient (3 year's old, female). Cosmetic results after treatment (ray amputation of $2^{\text {nd }}$ and $3^{\text {rd }}$ toes).

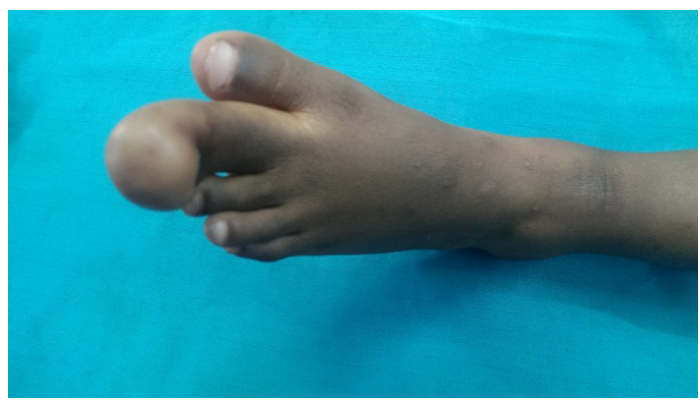

Figure 7: Patient, 6 years old, female with macrodactyly of $2^{\text {nd }}$ toe. 
showed the increase in size in width and length of the phalanges reached. The treatment was ray amputation of 2 nd toe (Figure 8 ), and cosmectic aspect before treatment (Figure 9) is not the same after treatment (Figure 10). The follow-up was of 6 months.

All operations were performed under general anesthesia by a single surgeon (KK). The ray amputations performed on each patient were similar in that they extended to the level of the tarsometatarsal joint. In addition to the metatarsal disarticulation, aggressive debulking of the adjacent soft-tissues were performed to allow for transpositon of the adjacent remaining metatarsals and narrowing of the foot. Primary closure was achieved in all patients. Common to all procedures, was the observation of marked excess of fibrous-fatty tissue and involvement of all tissue types.

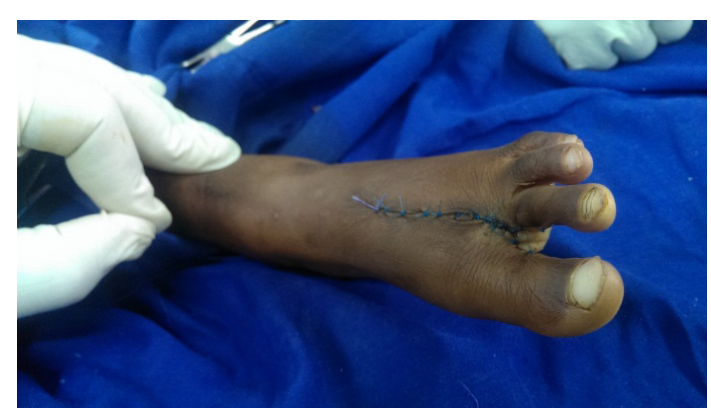

Figure 8: Ray amputation of 2nd toe, results after operation (same patient, 6 yeras old, female).

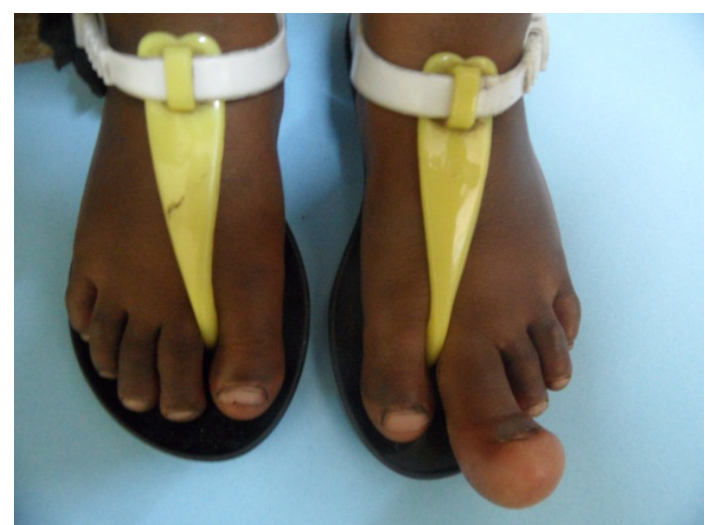

Figure 9: Cosmectic aspect before treatment (same patient, 6 years old female).

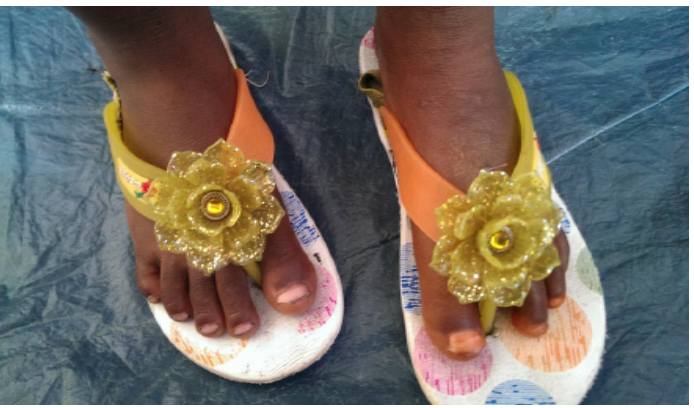

Figure 10: Comestic resuts after treatment, ray amputation of $2^{\text {nd }}$ toe (same patient, 6 yeras of old female).

\section{Discussion}

Macrodactyly is a rare congenital anomaly characterized by the congenital overgrowth of the bones and soft tissues in the fingers and toes.

In our serie, the second toe is the involved digits in all patients who are tree female and one male. Barsky, in a study of 64 cases, reported that macrodactyly is more commonly observed in males and in the foot the second digit is especially affected [4]. The study by Kotwal and Farooque, in which they inspected 23 cases, reported $61 \%$ of cases were in females and that the foot was more involved [11].

Treatment of macrodactyly of the foot in our serie is by ray amputation. Ray amputation remains the ideal method for the macrodactyly cases with accompanying metatarsal involvement. Primary advantages are the acceptable cosmetic results and the reduction in the size of the involved digit, which can only be achieved by this procedure $[1,3,12,13]$. But, we I believe the major value of the ray amputation approach is the degree to which the foot can be narrowed.

In all four of our cases, the final results are goods in terms of outcome (function, form). Function: patients are able to ambulate in normal footwear and carry on all activities of daily living. Form: all wounds healed well and patients were satisfied with the appearance of their foot and in addition, were able to wear the same size footwear on each foot.

Ray amputation is not suggested initially in macrodactyly of the great toe. A debulking procedure accompanied with/without phalangeal and/or metatarsal shortening and/or epiphysiodesis is preferred, likely because of the important role of the great toe in normal stepping and walking, as well as the unacceptable cosmetic result [3]. In a study on the cosmetic and functional importance of nail preservation, Dautel et al. performed a number of procedures for cases with macrodactyly of the great toe, including resection of the distal phalanx, debulking, and vascularized nail bed transfer [14]. Acceptable outcomes were obtained in all cases with the exception of stiffness in the proximal interphalangeal joint. Dedrick and Kling recommended complete ray amputation in young patients whose affected foot is two standard deviations away from the normal foot [12]. Similarly, Chang et al. noted that ray amputation is particularly indicated when the intermetatarsal angle is 10 or more degrees greater than normal [3].

\section{Conclusion}

Our results suggest that amputation of ray for severe macrodactyly of the foot is a effective treatment methode in a medical and surgical environment with limited resources, that provides acceptable cosmetic and functional results.

\section{References}

1. Bulut M, Karakurt L, Belhan O, Serbest S (2011) Ray amputation for the treatment of macrodactyly in the foot: report of three cases. Acta Orthop Traumatol Turc 45: 458-462.

2. Dennyson WG, Bear JN, Bhoola KD (1997) Macrodactyly in the foot. J Bone Joint Surg Br 59: 355-359.

3. Chang CH, Kumar SJ, Riddle EC, Glutting J (2002) Macrodactyly of the foot. J Bone Joint Surg Am 84:1189-1194.

4. Barsky AJ (1967) Macrodactyly. J Bone Joint Surg Am 49:1255-1266.

5. Turkington JR , Grey AC (2005) MR imaging of macrodystrophia lipomatosa Ulster Med J 74: 47-50.

6. Singla V, Virmani V, Tuli P, Singh P, Khandelwal N (2008) Case Report Macrodystrophia lipomatosa - Illustration of two cases. Indian J Radiol Imaging 18: $298-301$ 
Citation: Kibadi K (2014) Ray Amputation for Macrodractyly of the Foot: An Effective Treatment in an Environment With Limited Resources. Surgery Curr Res 4: 211. doi:10.4172/2161-1076.1000211

7. Fitoussi F, Ilharreborde B, Jehanno P, Frajman JM, Souchet P, et al. (2009) Macrodactyly. Chir Main 28: 129-137.

8. Tan O, Atik B, Dogan A, Alpaslan S, Uslu M (2006) Middle phalangectomy: a functional and aesthetic cure for macrodactyly. Scand J Plast Reconstr Surg Hand Surg 40: 362-365.

9. Cerrato F, Eberlin KR, Waters P, Upton J, Taghinia A, et al. (2013) Presentation and treatment of macrodactyly in children. J Hand Surg Am 38: 2112-2123.

10. Fransen BL, Broeders MG, van Oosterom FJ, Gilhuijs ND, Burger BJ (2014) Operative resection is a viable treatment of macrodactyly of the foot caused by lipofibromatous hamartoma : a case study with 5 year follo-up. Foot Ankle Surg 20: e47-50.

11. Kotwal PP, Farooque M, Macrodactyly (1998) J Bone Joint Surg Br 80: 651653.

12. Dedrick D, Kling TF Jr (1985) Ray resection in the treatment of macrodactyly of the foot in children. Orthop Trans 9: 145

13. Turra S, Santini S, Cagnoni G, Jacopetti T (1998) Gigantism of the foot: our experience in seven cases. J Pediatr Orthop 18: 337-345.

14. Dautel G, Vialaneix J, Faivre $S$ (2004) Island nail transfer in the treatment of macrodactyly of the great toe: a case report. J Foot Ankle Surg 43:113-118. 